\title{
High Heating Rate Devolatilization Kinetics of Pulverized Biomass Fuels
}

Johansen, Joakim M.; Jensen, Peter A.; Glarborg, Peter; De Martini, Nikolai; Ek, Paul; Mitchell, Reginald E.

Published in:

Energy and Fuels

Link to article, DOI:

10.1021/acs.energyfuels.8b03100

Publication date:

2018

Document Version

Peer reviewed version

Link back to DTU Orbit

Citation (APA):

Johansen, J. M., Jensen, P. A., Glarborg, P., De Martini, N., Ek, P., \& Mitchell, R. E. (2018). High Heating Rate Devolatilization Kinetics of Pulverized Biomass Fuels. Energy and Fuels, 32, 12955-12961.

https://doi.org/10.1021/acs.energyfuels.8b03100

\section{General rights}

Copyright and moral rights for the publications made accessible in the public portal are retained by the authors and/or other copyright owners and it is a condition of accessing publications that users recognise and abide by the legal requirements associated with these rights.

- Users may download and print one copy of any publication from the public portal for the purpose of private study or research.

- You may not further distribute the material or use it for any profit-making activity or commercial gain

- You may freely distribute the URL identifying the publication in the public portal

If you believe that this document breaches copyright please contact us providing details, and we will remove access to the work immediately and investigate your claim 


\title{
High Heating Rate Devolatilization Kinetics of Pulverized Biomass Fuels
}

\author{
Joakim M. Johansen, ${ }^{\dagger}$ Peter A. Jensen, ${ }^{\dagger}$ Peter Glarborg, ${ }^{* \dagger}{ }^{\dagger}$ Nikolai De Martini, ${ }^{\ddagger}$ \\ Paul Ek,,$^{\ddagger}$ and Reginald E. Mitchell \\ $\dagger$ Department of Chemical and Biochemical Engineering, Technical University of Denmark, \\ Denmark \\ $\ddagger$ Aabo Akademi University, Process Chemistry Centre, 20500 Turku, Finland \\ ฯStanford University, Mechanical Engineering Department, 94305 California, USA \\ E-mail: pg|@kt.dtu.dk
}

\begin{abstract}
Devolatilization kinetics for the biomass fuels miscanthus, leached miscanthus, and $\mathrm{KCl}$ doped pinewood were determined at high heating rates $\left(\sim 10^{5} \mathrm{~K} \cdot \mathrm{s}^{-1}\right)$, high peak temperatures $(1405-1667 \mathrm{~K})$, and short residence times $(<70 \mathrm{~ms})$. The particle temperature and residence time distribution were obtained from CFD simulations. The measured devolatilization rates, formulated in terms of single first order reactions, were significantly faster than data reported in literature. This difference was attributed partly to the fast heating rate/high temperature conditions of the present study, and partly to a more accurate estimate of the particle temperature. The current results indicate that neither the biomass type nor the alkali content of the biomass has a significant impact on the devolatilization rate under the investigated conditions. The development in the particle morphology was studied by electron microscopy as each fuel underwent partial to full conversion. The char yields ranged from 0.02 (leached
\end{abstract}


miscanthus) to 0.11 ( $\mathrm{KCl}$ doped pinewood), indicating that even during fast heating the biomass alkali content promotes char formation.

\section{Introduction}

In pulverized-fuel combustion of biomass, the particles experience very fast heating rates and high temperatures. The heating rate has been shown to be important for both the devolatilization rate and the char yield in combustion of solid fuels. Most reported studies of biomass devolatilization under conditions representative for pulverized fuel combustion have employed drop tube furnaces or entrained flow reactors. ${ }^{1-14}$ These studies have provided important data on devolatilization rates, as well as char yields and morphology. However, important issues are still in discussion.

Despite the interest in biomass pyrolysis under high heating rate, high temperature conditions, few reported kinetic studies have been reported for these conditions. Due partly to the uncertainty in the difficulties of estimating the particle temperature, measured rate constants show a significant scatter. Recently, Johansen et al. ${ }^{10}$ developed a methodology to obtain more reliable values. High heating rate experiments were conducted in an entrained flow reactor with small size fuel particles. Particles were extracted at known positions along the reactor, thus acquiring partially converted fuel samples. The temperature and residence time history were obtained numerically by means of computational fluid dynamic (CFD) simulations. The results obtained for pinewood (abbreviated as pine) indicated faster kinetics than found in other studies and lead to predicted residence times required for full conversion one order of magnitude lower than kinetics derived from thermogravimetric analysis (TGA). Such a difference has significant implications for ignition and flame stability in pulverized fuel firing. The limitation of the work of Johansen et al. ${ }^{10}$ was that it only covered one biomass; an extension of the work to a broader fuel range would be useful.

In addition to the influence on the devolatilization kinetic parameters, the heating rate 
is known to influence the biomass char yield. ${ }^{4,11,12,15}$ Low char yields of $1-6$ wt. \% (d.a.f) are reported for fast pyrolysis $\left(10^{4}-10^{5} \mathrm{~K} / \mathrm{s}\right)$ conditions while values as high as $15-17 \mathrm{wt} . \%$ (d.a.f) have been obtained at low heating rates $(10-20 \mathrm{~K} / \mathrm{min})$. Dall'Ora et al. ${ }^{4}$ showed how fast heating rate experiments resulted in melted chars while the fibrous structure of the parent fuel was retained if exposed to low heating rates.

Also the content of mineral matter in the fuel is known to influence the devolatilization process. Alkali metals have been found to act as catalysts for the decomposition process, promoting char formation. ${ }^{16-19}$ The char yield is thus affected by leaching or doping pretreatment of the fuel. Trubetskaya et al. ${ }^{20}$ showed a strong correlation between potassium content and char yield at heating rates of $10^{3} \mathrm{~K} / \mathrm{s}$, but data at even higher heating rates are scarce. ${ }^{4,11}$

The objective of this work is to provide kinetic data for the devolatilization of a wider range of biomass fuels at pulverized fuel combustion conditions, exposing biomass particles to high heating rates. The methodology of Johansen et al., ${ }^{10}$ described above, is followed again. The present work involves both major categories of biomass fuels relevant for heat and power production, i.e., herbaceous biomass and woody biomass. Annual crops are represented by miscanthus (a typical energy crop) in a high (parent fuel) and low (leached) ash state, while woody fuels are represented by pine, likewise in a high (doped) and low (parent fuel ${ }^{10}$ ) ash state. In addition to deriving pyrolysis kinetics, the char yield and morphology are characterized and the impact of the alkali metal content of the biomass devolatilization is investigated.

\section{Fuel Characterization}

Two biomass fuels, pine and miscanthus, have been used in this study. Pine is a high quality, low ash fuel, while miscanthus represents an annual crop biomass with a high ash content. To investigate systematically the impact of the potassium content, experiments 
were conducted with the fuels both in their parent state and with the K-content adjusted through pretreatment (doping or leaching). The fuel matrix thus involves both a low ash and a high ash state for both biomasses (pine and mischantus). Results for the parent pine were reported in our previous work. ${ }^{10}$

The woody fuel used in this study is a high quality commercial wood pellet made from Norwegian pine. The miscanthus has been provided by the Department of Agroecology at Aarhus University, Denmark. Proximate and ultimate analyses of the fuels are presented in Table 1. The ash phase is different both in quantity and composition. The miscanthus is naturally rich in both potassium and silicon. Washing the miscanthus results in significant leaching of potassium and chlorine, while the silicon content remains high. The pine sample was doped with $\mathrm{KCl}$ doping to attain a level of potassium similar to that of the parent miscanthus.

Table 1: Proximate and ultimate analysis of the investigated fuels and mineral states. Volatile fractions have been determined according to standard DS/EN 15148:2009.

\begin{tabular}{llcccc}
\hline & Unit & $\begin{array}{c}\text { Pine } \\
\text { Parent }\end{array}$ & $\begin{array}{c}\text { Pine } \\
\text { KCl doped }\end{array}$ & $\begin{array}{c}\text { Miscanthus } \\
\text { Parent }\end{array}$ & $\begin{array}{c}\text { Miscanthus } \\
\text { Leached }\end{array}$ \\
\hline Ash & wt. \% (dry) & 0.2 & 1.2 & 3.4 & 0.8 \\
Volatile & & 82.4 & 77.6 & 77.8 & 85.7 \\
$\mathrm{HHV}$ & $\mathrm{MJ} / \mathrm{kg}($ dry) & 20.58 & 20.79 & 19.28 & 19.64 \\
$\mathrm{LHV}$ & & 19.23 & 19.45 & 17.97 & 18.31 \\
\hline $\mathrm{C}$ & wt. \% (dry) & 51.5 & 51.7 & 48.5 & 49.9 \\
$\mathrm{H}$ & & 6.2 & 6.2 & 6.0 & 6.1 \\
$\mathrm{~N}$ & & $<0.20$ & $<0.2$ & 0.45 & 0.31 \\
$\mathrm{~S}$ & & 0.007 & 0.007 & 0.065 & 0.027 \\
$\mathrm{Cl}$ & & 0.016 & 0.47 & 0.30 & 0.007 \\
$\mathrm{Al}$ & $\mathrm{mg} / \mathrm{kg}($ dry $)$ & 32 & 20 & 270 & $<10$ \\
$\mathrm{Ca}$ & & 950 & 430 & 1100 & 870 \\
$\mathrm{Fe}$ & & 26 & 36 & 270 & 180 \\
$\mathrm{~K}$ & & 480 & 5700 & 7900 & 330 \\
$\mathrm{Mg}$ & & 140 & 40 & 540 & 330 \\
$\mathrm{Na}$ & & 95 & 33 & 340 & $<10$ \\
$\mathrm{P}$ & 52 & $<20$ & 740 & 200 \\
$\mathrm{Si}$ & & $<200$ & $<200$ & 6200 & 2100 \\
$\mathrm{Ti}$ & & $<5.0$ & $<5.0$ & 13 & $<5.0$ \\
\hline
\end{tabular}


The fuels were crushed and subsequently milled in a rotating cutter mill equipped with laboratory accuracy screens, separating the fuels in well defined size fractions: $63-90 \mu \mathrm{m}$ and $106-125 \mu \mathrm{m}$. The resulting dusts were analyzed by two-dimensional image analysis using a Netzsch CAMSIZER XT ${ }^{\circledR}$. The characteristic length describing a sphere with a similar $V / A$-ratio can be approximated by the Martin minimum diameter, as discussed in the work of Trubetskaya. ${ }^{21}$ A Rosin-Rammler distribution is used to describe the particle size distribution,

$$
Y_{\mathrm{d}}=\exp \left[-\left(\frac{d}{\bar{d}}\right)^{n}\right]
$$

where $\bar{d}$ and $n$ are the Rosin-Rammler mean diameter and the distribution spread. The Rosin-Rammler parameters that define the particle size range are summarized in Table 2 .

Table 2: Summary of the Rosin-Rammler parameter used to describe the included fuels.

\begin{tabular}{lcccc}
\hline Size fraction & \multicolumn{2}{c}{$63-90 \mu \mathrm{m}$} & \multicolumn{2}{c}{$106-125 \mu \mathrm{m}$} \\
Rosin RAmmler parameters & $\bar{d} / \mu \mathrm{m}$ & $n$ & $\bar{d} / \mu \mathrm{m}$ & $n$ \\
\hline Pine & 53.6 & 2.41 & 78.8 & 2.45 \\
KCl doped pine & 45.9 & 1.92 & 63.2 & 2.00 \\
Miscanthus & 52.7 & 2.13 & 90.8 & 2.92 \\
Leached miscanthus & 58.9 & 2.56 & 86.0 & 2.98 \\
\hline
\end{tabular}

\section{Treatment of the Mineral Content}

Prior to milling, the miscanthus was leached in a $15 \mathrm{~L}$ plastic bucket half filled with uncut fuel (volume based without compression) and topped off with deionized water. A propeller was inserted and vigorous stirring was applied. The water was changed every 24 hours until a total of 72 hours were reached. The water was drained and the fuel was washed with ultra pure water on a sieve. Afterwards the fuel was dried at $333 \mathrm{~K}$ until reaching a moisture level below 2 wt. $\%$.

In the process of doping the pine, the sample was cut to powder using a cutter mill and a $4 \mathrm{~mm}$ screen (producing a fine powder). The sample was soaked briefly in a $73.8 \mathrm{mM}$ solution of $\mathrm{KCl}$ in ultra pure water. Excess solution was drained by means of a büchner funnel, a low 
powered vacuum pump, and a fibre glass filter with a $75 \mu \mathrm{m}$ cut-off. The wet cake was left to dry at $333 \mathrm{~K}$ until the moisture content had dropped below 2 wt. $\%$.

\section{Methodology}

The current work follows the methodology developed earlier by the authors. ${ }^{10}$ High temperature conditions are established by feeding the solid fuel into a laminar flow reactor (LFR) ${ }^{10,22,23}$ heated by a $\mathrm{CH}_{4} / \mathrm{H}_{2}$ understoichiometric pilot flame. This configuration facilitated adiabatic flame temperatures of $1405-1667 \mathrm{~K}$ and particle heating rates on the order of $10^{5} \mathrm{~K} / \mathrm{s}$. The partially or fully reacted particles are collected by a water cooled and helium quenched probe at particle residence times between 4 and $200 \mathrm{~ms}$.

The low ash fraction and the high volatility of some of the inorganic species, such as alkali metals and halides, make it difficult to use ash as a tracer. To circumvent bias from the release of volatile ash components, we again use calcium as a tracer. ${ }^{10}$ The degree of conversion is calculated by closing a Ca mass balance on the collected char:

$$
\chi=\frac{w_{\mathrm{Ca}}-w_{\mathrm{Ca}, 0}}{w_{\mathrm{Ca}}\left(1-w_{\mathrm{ash}, 0}\right)}
$$

where $w_{\mathrm{Ca}}$ and $w_{\mathrm{Ca}, 0}$ are the weight percent of calcium in the char sample and in the parent fuel, respectively, while $w_{\mathrm{ash}, 0}$ is the weight percent of ash in the parent fuel.

The particle residence times and temperature histories are calculated by multiphase reacting flow CFD simulations. All simulations are carried out using ANSYS Fluent 15.0.7. The CFD model describes the reactor from the fuel inlet and $0.25 \mathrm{~m}$ downstream in an axisymmetric representation of the domain. The pilot flame is assumed to be in thermodynamic equilibrium and thus modeled as exhaust gases entering the domain at the adiabatic flame temperature. Any reaction between fuel particles and species in the flame exhaust is neglected. Internal gradients in the particles are neglected due to their small size. The effect of the change in heat capacity during devolatilization is accounted for, ${ }^{10}$ while the impact 
on the heat transfer of gasses emitted has been disregarded. The gaseous flux away from the particle is detrimental to convective heat transfer, but the effect on the particle temperature is comparatively small. ${ }^{24,25}$ The detailed model specification including inlet and boundary conditions is described in the original work of Johansen et al. ${ }^{10}$

The simulations of the reacting particles are coupled to the experiments by iteratively updating the devolatilization kinetics applied in the CFD simulations, until the calculated mass loss agrees with the measurements. The devolatilization is described by a single first order reaction (SFOR) with an Arrhenius type rate expression:

$$
\frac{\mathrm{d} V(t)}{\mathrm{d} t}=A \exp \left[\frac{-E_{\mathrm{a}}}{R T(t)}\right]\left(V^{*}-V(t)\right)
$$

where $V$ is the released volatile matter at time $t$ and $V^{*}$ is the high heating rate, high temperature volatile content, assumed to be constant in this study. The rate expression is fitted using the pre-exponential factor, $A$, and the activation energy, $E_{\mathrm{a}}$, evaluated at the particle temperature, $T$. The universal gas constant is denoted $R$. The devolatilization is assumed to be isothermic. A more accurate description of the devolatilization behavior may be achieved by using a parallel reaction scheme, ${ }^{26}$ but this is outside the scope of the present work.

To facilitate comparison of the devolatilization reactivity of the pine with literature data, a low heating rate TGA analysis was carried out. Fuel samples of 2-6 mg, milled and sieved to 63-90 Âtm, were analyzed using a Netzsch STA 449 F1. The samples were dried out at $378 \mathrm{~K}$ in a pure nitrogen atmosphere and then heated to $1273 \mathrm{~K}$ at heating rates of $2 \mathrm{~K} / \mathrm{min}$.

\section{Results and discussion}

This section presents the results of the current study for the doped pine and the parent and leached miscanthus. The data are compared to those of the parent pine. ${ }^{10}$ 


\section{Development in Char Morphology}

The development in char morphology as the fuel particles undergo partial and eventually full devolatilization is shown in Fig. 1 for an adiabatic flame temperature of $1566 \mathrm{~K}$. The conversion profiles are calculated based on the Ca-balance of the partially reacted particles. All fuel samples are needle-shaped with high initial aspect ratios in their virgin state. As devolatilization progresses, the fuel particles gradually loose their structure and transform into spherical geometries, seemingly through a melted phase. Only the leached miscanthus tends to retain some of its needle shape structure throughout the devolatilization. Conceivably this is due to its high content of silicon; previous work ${ }^{12}$ indicates that silicon-rich fuels have a larger tendency to retain the particle morphology during pyrolysis.

\section{Devolatilization Kinetics}

The devolatilization kinetics are estimated based on the assumption of a first order single step mechanism. This way, the kinetic results are presented in a form that facilitates implementation into CFD solvers. The Arrhenius parameters, derived from the experimental data by running the iterative algorithm, are listed in Table 3 for the four fuels.

Table 3: Overview of the resulting apparent devolatilization kinetics. The data for pine were drawn from Johansen et al. ${ }^{10}$

\begin{tabular}{cccccc}
\hline & & Pine & Miscanthus & KCl doped pine & Leached miscanthus \\
\hline$A$ & $\times 10^{3} \mathrm{~s}^{-1}$ & 18.9 & 20.5 & 14.8 & 13.7 \\
$E_{\mathrm{a}}$ & $\mathrm{J} \cdot \mathrm{mol}^{-1}$ & 21305 & 17891 & 14350 & 13511 \\
\hline
\end{tabular}

Figure 2 compares the experimental data for the $1566 \mathrm{~K}$ (adiabatic) flame with the simulation results, using the Arrhenius parameters listed in Table 3. Standard deviations for the pine experiments were reported by Johansen et al. ${ }^{10}$ The deviations for the present experiments are of the same magnitude, but they are not shown here to avoid clutter. The uncertainty in the data, determined by the reliability of both the experimental methods (including using $\mathrm{Ca}$ as a tracer) and the particle temperature estimation by CFD, is significant 


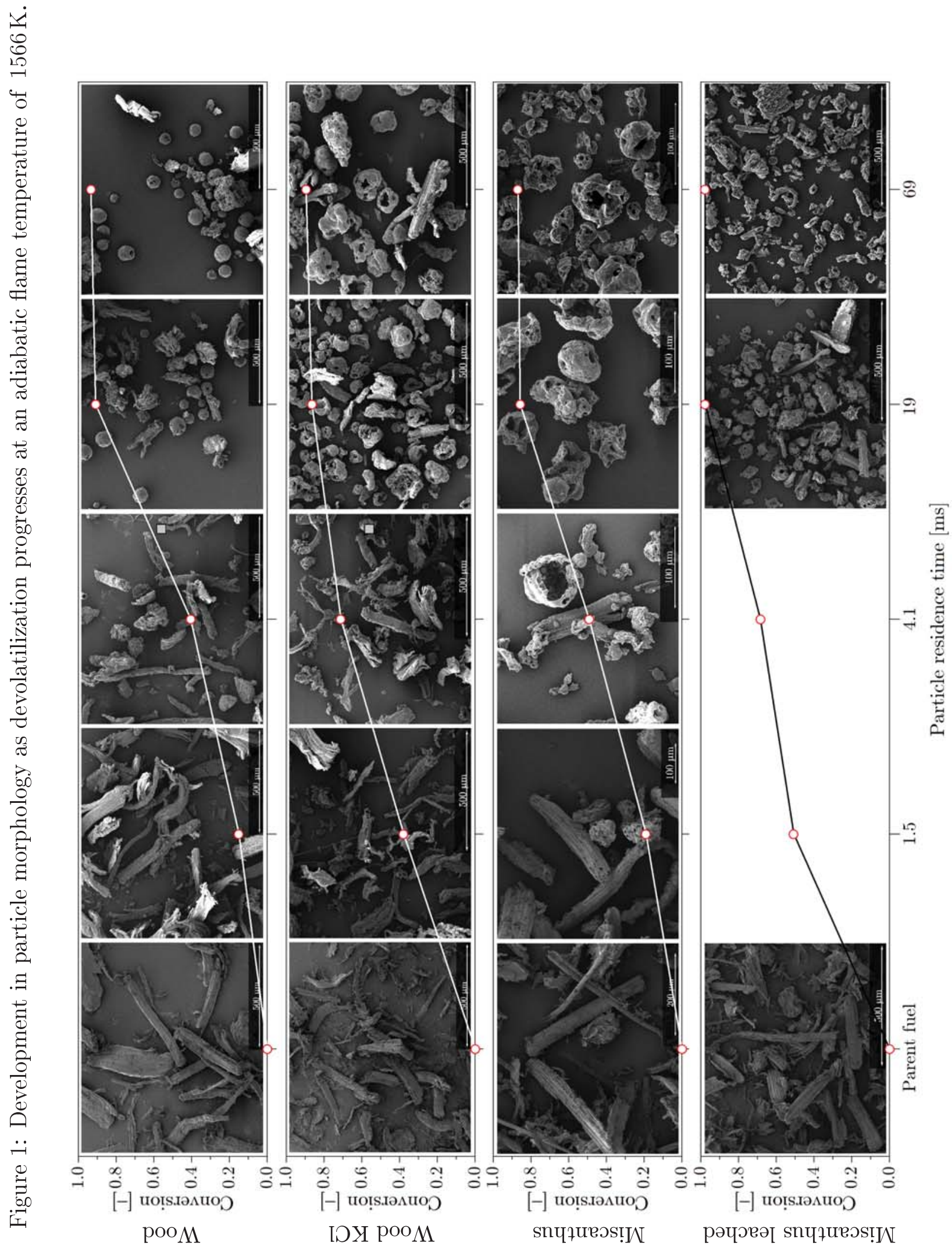


at lower fuel conversions, while the error is small at high levels of conversion. However, the error has only a limited impact on the derived Arrhenius parameters due to the strong gradients. The applied kinetics appear to capture the rapid conversion well for all four fuels.

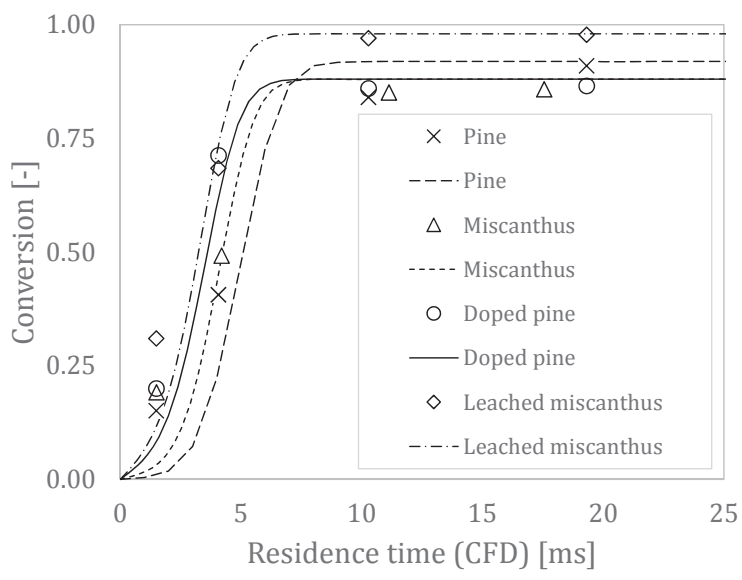

Figure 2: Comparison of experimental data and modeling predictions for the degree of devolatilization for the four fuels for the condition with an adiabatic flame temperature of $1566 \mathrm{~K}$. The results for parent pine were drawn from Johansen et al. ${ }^{10}$

An Arrhenius plot comparing the rate constants for the four fuels is shown in Fig. 3. Based on earlier modeling work, ${ }^{27}$ where kinetic parameters derived from experiments using high and low temperature equipment were compared, the rate constants derived in the current work are applicable at particle temperatures above $800 \mathrm{~K}$. The data shown in the Arrhenius plot indicate that the rate constant for the low ash content pine $(0.2$ wt. \%) is smaller than those of the higher ash content fuels; leached miscanthus ( 0.8 wt. \%), $\mathrm{KCl}$ doped pine (1.2wt. \%), and parent miscanthus (3.4wt.\%). However, we believe that the differences are within the statistical uncertainty in the parameter evaluation. The present results indicate that neither the biomass type nor the alkali content of the biomass has a significant impact on the devolatilization rate under the investigated conditions.

In Fig. 4, the present rate constants are compared with selected data from literature. The literature data were chosen to represent common methods for determining devolatilization kinetics. Kinetic studies are commonly conducted in a TGA at heating rates of the order of kelvins per minute. ${ }^{28}$ This approach offers accurate temperature and mass loss curves. 


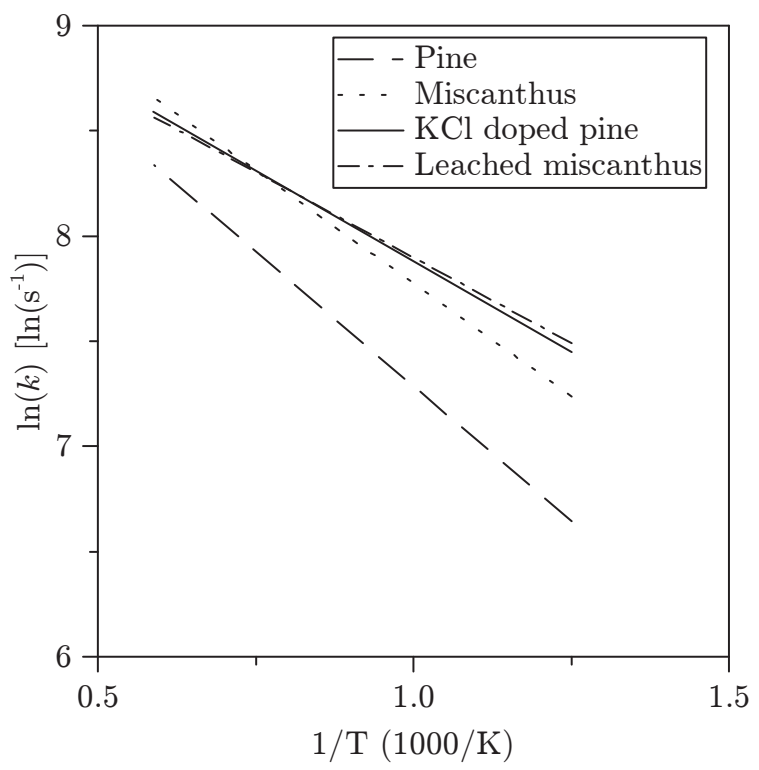

Figure 3: Comparison across the different fuel types of the high temperature, high heating rate rate constants obtained in the present work.

The drawback of the TGA approach is that the low heating rate results in kinetics that are not representative for high heating rate processes. ${ }^{28,29}$ This limitation is confirmed by the present results; the TGA rate constant for pine is much lower than the fast heating rate data, even when extrapolated to high temperature (Fig. 4).

As discussed by Solomon et al., ${ }^{24}$ it is crucial to estimate correctly the particle temperature when deriving pyrolysis kinetics. Bonvicini et al. ${ }^{30}$ used a high temperature drop tube furnace and derived the kinetics under the assumption that the particles assume the reactor temperature instantaneously upon introduction to the furnace. This approach neglects the particle heating period during which devolatilization occurs at lower temperatures than assumed. This in turn results in net lower rate constants, as seen in Fig. 4.

Similar to the present work, Simone et al. ${ }^{29}$ used an entrained flow reactor and calculated the temperature profiles using CFD. Their work provides kinetic data most similar to the current study. However, the temperatures in their study were limited to $800 \mathrm{~K}$ and below; we believe that this is the reason for their rate constant being somewhat smaller than those of the current study. The difference indicates that both high heating rate and high peak 


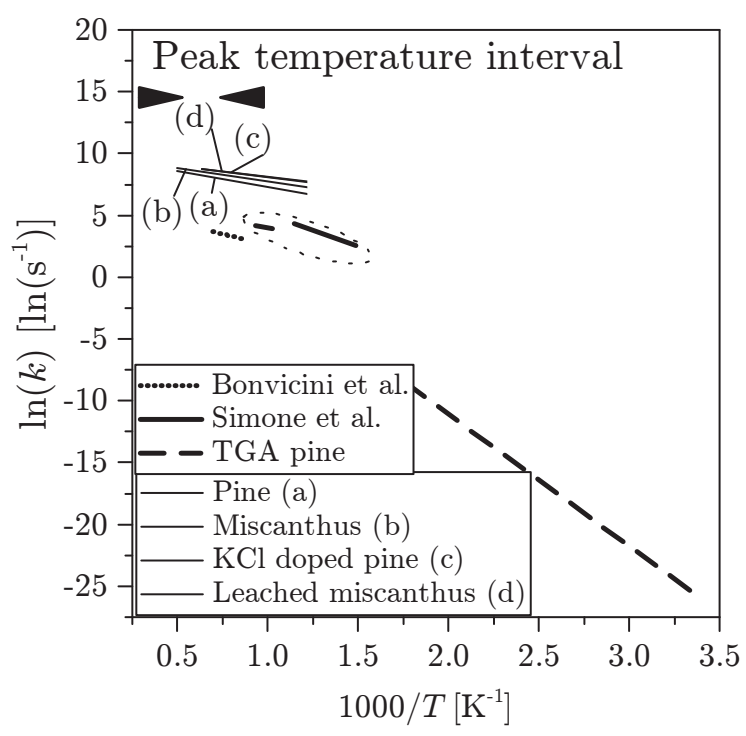

Figure 4: Comparison of the rate constants for (a) pine, (b) miscanthus, (c) $\mathrm{KCl}$ doped pine, and (d) leached miscanthus. Current work is compared to literature data of pine experiments with slow heating rate (TGA, current study), high heating rate without temperature correction (Bonvicini et al. ${ }^{30}$ ), and high heating rate experiments at low peak temperatures (Simone et al. ${ }^{29}$ ).

temperature are necessary to represent particle devolatilization at power plant conditions.

In Supplementary Material, a more comprehensive comparison of the present data with devolatilization rate constants from literature is made. Most reported studies are still limited to heating rates on the order of $10^{3} \mathrm{~K} \cdot \mathrm{s}^{-1}$ or below. The kinetics of the current study are signicantly faster than the majority of data reported in the literature.

Activation energies for biomass devolatilization at high heating rates from the present work and reported in literature ${ }^{10,31,32}$ are lower than those obtained at low heating rates. ${ }^{32-40}$ On the other hand, high activation energies have been reported for high heating rate coal pyrolysis, ${ }^{24}$ and used successfully for single reaction devolatilization in CFD models for combustion of both coal ${ }^{41}$ and biomass. ${ }^{42}$ Several factors may influence the particle temperature estimate and thereby the calculated activation energy. In the present work we assume pyrolysis to be thermo-neutral, but if it proceeds as an endothermic process, ${ }^{43,44}$ it will affect the particle temperature. The effect of the heat of reaction has been evaluated in several numerical studies. ${ }^{45-47}$ However, Saddawi et al. ${ }^{48}$ have shown that the activation energy ob- 
tained for high temperature, high heating rates is related to the choice of model (single step or multi-step reaction) and that similar predictions can be obtained over a wide range of values.

\section{Char Yield}

The volatile fraction, calculated based on the Ca mass balance, is shown in Fig. 5. The error bars indicate the experimental and the conditional standard deviation. The high ash content fuels, miscanthus and $\mathrm{KCl}$-doped pine, produce the highest amount of char on a dry and ash free basis. This is expected since alkali matter in the inorganic phase has been shown to promote char formation. ${ }^{11,20}$ The ash phase of the leached miscanthus is dominated by a large Si content that does not influence the organic char yield.

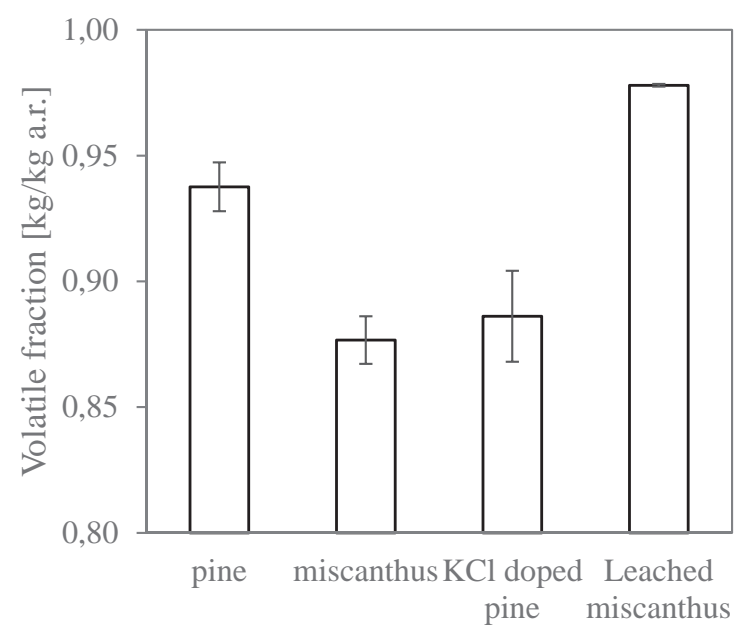

Figure 5: Comparison of the volatile fraction (dry and ash free) of the different fuels averaged over experiments and reactor temperatures (1378-1566 K).

The volatile content in the fuel on an as-received basis makes up a significant amount of the fuel on both a weight and an energy basis. When comparing the results to the standard fuel analysis (Table 1), significantly larger fractions of volatiles are released during devolatilization at high temperatures. This is expected since the proximate analysis is known to underestimate the volatile yield under pulverized fuel combustion conditions. 
Figure 6 compares the char yield based on the potassium content. The results are in good agreement with data reported by Trubetskaya et al. ${ }^{11,20}$ who tested the influence of the potassium content at different drop tube reactor temperatures (1273-1673 K) with fuel varying in potassium content $\left(80-28,000 \mathrm{mg} \cdot \mathrm{kg}^{-1}\right)$. The data show that presence of potassium promotes the char yield, even at the high heating rates investigated in these studies. They confirm the trends observed by Leth-Espensen et al. ${ }^{15}$ based on a broader data material.

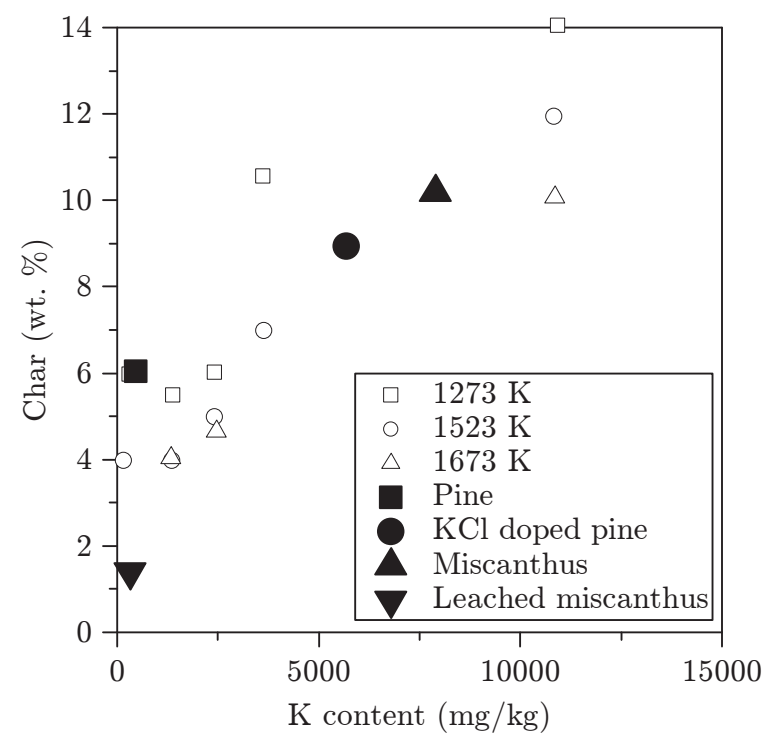

Figure 6: Comparison of the char residue of the different fuels based on potassium content. Results are averaged over experiments and reactor temperatures (1378-1566 K). Solid symbols represents data from the current study while open symbols denote data from Trubetskaya et al. ${ }^{11,20}$

\section{Practical Implications}

Computational Fluid Dynamics (CFD) have become an important tool for the power plant companies to assess the importance of burner geometry, fuel properties, and operating conditions. Conversion from fossil fuels such as coal to pulverized biomass involves a range of technical challenges, including flame stabilization and burnout. The fibrous structure of the biomass results in a more energy-intensive and less efficient milling process, leading to particle sizes larger than those typical for pulverized coal. The devolatilization rate of 
the larger particles is controlled to a significant degree by heat transfer limitations, but the volatile release rate for the smaller particles, important for ignition and flame stabilization, is largely determined by the kinetics. We recommend that the kinetics derived in the present work are used when the devolatilization is represented by a single first-order reaction. Preliminary (unpublished) CFD calculations for full scale bio-dust fired burners indicate that replacing standard devolatilization kinetics in CFD with the current fast kinetics can have strong implications for the predicted flame stabilization, providing improved agreement with measurement.

\section{Conclusions}

The single step first order devolatilization kinetics of a range of biomass fuels were determined in a flow reactor under high temperature, high heating rate conditions. The selected fuels covered a wide range of both silicon and ash content, representing the macro properties of both high quality woody biomass and the more difficult annual crops. The particle temperature and residence time distribution were obtained from CFD simulations, enabling accurate devolatilization kinetics to be derived at conditions similar to those of pulverized fuel combustion. The devolatilization rates determined this way are significantly faster than results reported in literature; the difference is attributed to the high heating rate and peak temperature in the flow reactor. The present results indicate that neither the biomass type nor the alkali content of the biomass has a significant impact on the devolatilization rate under the investigated conditions. The present kinetics are recommended for pulverized fuel conditions and other applications with heating rates of the order of $10^{3}-10^{5} \mathrm{~K} \cdot \mathrm{s}^{-1}$. However, for use in commercial CFD solvers it has to be combined with descriptions of particle heating and low-temperature kinetics, possibly along the lines described by Johansen et al. ${ }^{27}$ The volatile fraction is significantly higher when the fuel is treated at high temperatures and high heating rates compared to a low temperature treatment. This trend is seen for all fuels. 
The char yield is influenced to a noticeable degree by the ash content. The promoting effect of alkali content on the char yield agrees well with literature results for high temperature pyrolysis of biomass.

\section{Acknowledgement}

This work is part of the Power Generation from Renewable Energy (GREEN) Research Centre funded by the Danish Council for Strategic Research who are gratefully acknowledged.

\section{References}

(1) Brown, A. L.; Dayton, D. C.; Daily, J. W. A study of cellulose pyrolysis chemistry and global kinetics at high heating rates. Energy Fuels 2001, 15, 1286-1294.

(2) Jimenez, S.; Remacha, P.; Ballesteros, J. C.; Gimenez, A.; Ballester, J. Kinetics of devolatilization and oxidation of a pulverized biomass in an entrained flow reactor under realistic combustion conditions. Combust. Flame 2008, 152, 588-603.

(3) Lu, H.; Robert, W.; Peirce, G.; Ripa, B.; Baxter, L. L. Comprehensive study of biomass particle combustion. Energy Fuels 2008, 22, 2826-2839.

(4) Dall'Ora, M.; Jensen, P. A.; Jensen, A. D. Suspension Combustion of Wood: Influence of Pyrolysis Conditions on Char Yield, Morphology, and Reactivity. Energy Fuels 2008, 22, $2955-2962$.

(5) Biagini, E.; Simone, M.; Tognotti, L. Characterization of high heating rate chars of biomass fuels. Proc. Combust. Inst. 2009, 32, 2043-2050.

(6) Dupont, C.; Chen, L.; Cances, J.; Commandre, J.-M.; Cuoci, A.; Pierucci, S.; Ranzi, E. Biomass pyrolysis: Kinetic modelling and experimental validation under high temperature and flash heating rate conditions. J. Anal. Appl. Pyrol. 2009, 85, 260-267. 
(7) Umeki, K.; Kirtania, K.; Chen, L.; Bhattacharya, S. Fuel Particle Conversion of Pulverized Biomass during Pyrolysis in an Entrained Flow Reactor. Ind. Eng. Chem. Res. 2012, 51, 13973-13979.

(8) Li, T.; Wang, L.; Ku, X.; Guell, B. M.; Lovas, T.; Shaddix, C. R. Experimental and Modeling Study of the Effect of Torrefaction on the Rapid Devolatilization of Biomass. Energy Fuels 2015, 29, 4328-4338.

(9) Zellagui, S.; Schonnenbeck, C.; Zouaoui-Mahzoul, N.; Leyssens, G.; Authier, O.; Thunin, E.; Porcheron, L.; Brilhac, J. F. Pyrolysis of coal and woody biomass under $\mathrm{N}_{2}$ and $\mathrm{CO}_{2}$ atmospheres using a drop tube furnace - experimental study and kinetic modeling. Fuel Process. Technol. 2016, 148, 99-109.

(10) Johansen, J. M.; Gadsbøll, R.; Thomsen, J.; Jensen, P. A.; Glarborg, P.; De Martini, N.; Ek, P.; Mancini, M.; Weber, R.; Mitchell, R. E. Devolatilization of Woody Biomass at Short Residence Times and High Heating Rates and Peak Temperatures. Appl. Energy 2016, 162, 245-256.

(11) Trubetskaya, A.; Jensen, P. A.; Jensen, A. D.; Garcia Llamas, A. D.; Umeki, K.; Glarborg, P. Effect of fast pyrolysis conditions on biomass solid residues at high temperatures. Fuel Process. Technol. 2016, 143, 118-129.

(12) Trubetskaya, A.; Arendt Jensen, P.; Degn Jensen, A.; Steibel, M.; Spliethoff, H.; Glarborg, P.; Larsen, F. H. Comparison of high temperature chars of wheat straw and rice husk with respect to chemistry, morphology and reactivity. Biomass Bioenergy 2016, $86,76-87$.

(13) Holmgren, P.; Wagner, D. R.; Strandberg, A.; Molinder, R.; Wiinikka, H.; Umeki, K.; Brostrom, M. Size, shape, and density changes of biomass particles during rapid devolatilization. Fuel 2017, 206, 342-351. 
(14) Niemela, N. P.; Tolvanen, H.; Saarinen, T.; Leppanen, A.; Joronen, T. CFD based reactivity parameter determination for biomass particles of multiple size ranges in high heating rate devolatilization. Energy 2017, 128, 676-687.

(15) Leth-Espensen, A.; Glarborg, P.; Jensen, P. Predicting Biomass Char Yield from High Heating Rate Devolatilization using Chemometrics. Energy Fuels 2018, 32, 9572-9580.

(16) Raveendran, K.; Ganesh, A.; Khilart, K. C. Influence of Mineral Matter on Biomass Pyrolysis Characteristics. Fuel 1995, 74, 1812-1822.

(17) Nik-Azar, M.; Hajaligol, M. M. R.; Sohrabi, M.; Dabir, B. Mineral matter effects in rapid pyrolysis of beech wood. Fuel Process. Technol. 1997, 51, 7.

(18) Jensen, A.; Dam-Johansen, K.; Wo, M. A.; Serio, M. A. TG-FTIR Study of the Influence of Potassium Chloride on Wheat Straw Pyrolysis. Energy Fuels 1998, 12, 929-938.

(19) Jones, J.; Darvell, L.; Bridgeman, T.; Pourkashanian, M.; Williams, A. An investigation of the thermal and catalytic behaviour of potassium in biomass combustion. Proc. Combust. Inst. 2007, 31, 1955-1963.

(20) Trubetskaya, A.; Jensen, P. A.; Jensen, A. D.; Steibel, M.; Spliethoff, H.; Glarborg, P. Influence of fast pryolysis conditions on yield and structural transformation of biomass chars. Fuel Process. Technol. 2015, 140, 205-214.

(21) Trubetskaya, A. Single Biomass Particle Combustino and Fuel Characterization. PhD thesis, Technical University of Denmark, 2015.

(22) Campbell, P. A.; Mitchell, R. E.; Ma, L. Characterization of Coal Char and Biomass Char Reactivities to Oxygen. Proc. Combust. Inst. 2002, 29, 519-526.

(23) Ma, L.; Mitchell, R. Modeling Char Oxidation Behavior under Zone II Burning Conditions at Elevated Pressures. Combust. Flame 2009, 156, 37-50. 
(24) Solomon, P. R.; Serio, M. A.; Carangelo, R. M.; Markham, J. R. Very Rapid Coal Pyrolysis. Fuel 1986, 65, 182-194.

(25) Solomon, P. R.; Serio, M. A.; Suuberg, E. M. Coal Pyrolysis - Experiments, Kinetic Rates and Mechanisms. Prog. Energy Combust. Sci. 1992, 18, 133-220.

(26) Hayhurst, A. N. The kinetics of the pyrolysis or devolatilisation of sewage sludge and other solid fuels. Combust. Flame 2013, 160, 138-144.

(27) Johansen, J. M.; Jensen, P. A.; Glarborg, P.; Mancini, M.; Weber, R.; Mitchell, R. E. Extension of Apparent Devolatilization Kinetics from Thermally Thin to Thermally Thick Particles in Zero Dimensions for Woody Biomass. Energy 2016, 95, 279-290.

(28) Johansen, J. M.; Aho, M.; Paakkinen, K.; Taipale, R.; Egsgaard, H.; Jakobsen, J. G.; Frandsen, F. J.; Glarborg, P. Release of K, Cl, and S during combustion and cocombustion with wood of high-chlorine biomass in bench and pilot scale fuel beds. Proc. Combust. Inst. 2013, 34, 2363-2372.

(29) Simone, M.; Biagini, E.; Galletti, C.; Tognotti, L. Evaluation of Global Biomass Devolatilization Kinetics in a Drop Tube Reactor with CFD Aided Experiments. Fuel 2009, 88, 1818-1827.

(30) Bonvicini, G.; Coraggio, G.; Faleni, M. Biofuels Devolatilization and Char Combustion Characterization with the IPFR; International Flame Research Foundation, 2013.

(31) Hajaligol, M. R.; Howard, J. B.; Longwell, J. P.; Peters, W. A. Product composition and kinetics for rapid pyrolysis of cellulose. Ind. Eng. Chem. Process Des. Dev. 1982, 21, 457-465.

(32) Antal, M. J. J.; Várhegyi, G. Cellulose Pyrolysis Kinetics: The Current State of Knowledge. Ind. Eng. Chem. Res. 1995, 34, 703-717. 
(33) Akita, K.; Kase, M. Determination of Kinetic parameters for pyrolysis of cellulose and cellulose treated with ammonium phosphate by differential thermal analysis and thermal gravimetric analysis. J. Polym. Sci. Part A-1 Polym. Chem. 1967, 5, 833-848.

(34) Min, K. Vapor-phase thermal analysis of pyrolysis products from cellulosic materials. Combust. Flame 1977, 30, 285-294.

(35) Fairbridge, C.; Ross, R. A.; Sood, S. P. A Kinetic and Surface Study of the Thermal Decomposition of Cellulose Powder in Inert and Oxidizipg Atmospheres. J. Appl. Polym. Sci. 1978, 22, 497-510.

(36) Antal, M. J. J.; Friedmand, H. L.; Rogers, F. E. Kinetics of Cellulose Pyrolysis in Nitrogen and Steam. Combust. Sci. Technol. 1980, 21, 141-152.

(37) Bilbao, R.; Arauzo, J.; Millera, A. Kinetics of thermal decomposition of cellulose. Part I. Influence of experimental conditions. Thermochim. Acta 1987, 120, 121-131.

(38) Bilbao, R.; Arauzo, J.; Millera, A. Kinetics of thermal decomposition of cellulose. Part II. Temperature differences between gas and solid at high heating rates. Thermochim. Acta 1987, 120, 133-141.

(39) Várhegyi, G.; Antal, M. J. J. Kinetics of the thermal decomposition of cellulose, hemicellulose, and sugar cane bagasse. Energy Fuels 1989, 3, 329-335.

(40) Grønli, M.; Antal, M. J.; Várhegyi, G. A Round-Robin Study of Cellulose Pyrolysis Kinetics. Ind. Eng. Chem. Res. 1999, 38, 2238-2244.

(41) Jones, J. M.; Patterson, P. M.; Pourkashanian, M.; Williams, A.; Arenillas, A.; Rubiera, F.; Pis, J. J. Modelling NOx formation in coal particle combustion at high temperature: an investigation of the devolatilisation kinetic factors. Fuel 1999, 78, $1171-1179$. 
(42) Ma, L.; Jones, J. M.; Pourkashanian, M.; Williams, A. Modelling the combustion of pulverized biomass in an industrial combustion test furnace. Fuel 2007, 86, 1959-1965.

(43) Milosavljevic, I.; Oja, V.; Suuberg, E. M. Thermal Effects in Cellulose Pyrolysis: Relationship to Char Formation Processes. Ind. Eng. Chem. Res. 1996, 35, 653-662.

(44) Rath, J.; Wolfinger, M. G.; Steiner, G.; Krammer, G.; Barontini, F.; Cozzani, V. Heat of Wood Pyrolysis. Fuel 2003, 82, 81-91.

(45) Simmons, G. M.; Gentry, M. Particle size limitations due to heat transfer in determining pyrolysis kinetics of biomass. J. Anal. Appl. Pyrolysis 1986, 10, 117-127.

(46) Kothari, V.; Antal Jr., M. J. Numerical studies of the flash pyrolysis of cellulose. Fuel 1985, 64, 1487-1494.

(47) Narayan, R.; Antal, M. J. J. Thermal Lag, Fusion, and the Compensation Effect during Biomass Pyrolysis. Ind. Eng. Chem. Res. 1996, 35, 1711-1721.

(48) Saddawi, A.; Jones, J. M.; Williams, A.; Wojtowicz, M. A. Kinetics of the Thermal Decomposition of Biomass. Energy Fuels 2010, 24, 1274-1282. 